Bull. Chem. Soc. Ethiop. 2016, 30(1), 147-151.

Printed in Ethiopia

DOI: http://dx.doi.org/10.4314/bcse.v30i1.14

ISSN 1011-3924

(c) 2016 Chemical Society of Ethiopia

\title{
FT-IR, RAMAN AND DFT STUDIES ON THE VIBRATIONAL SPECTRA OF 2,2-BIS(AMINOETHOXY)PROPANE
}

\author{
ÖzgürAlver* \\ Department of Physics, Science Faculty, Anadolu University, Eskişehir, Turkey
}

(Received November 20, 2014; revised November 5, 2015)

\begin{abstract}
Various structural forms and molecular structures of 2,2-bis(aminoethoxy)propane (baep) were examined both experimentally and theoretically including FT-IR and Raman spectroscopic methods. Among the possible structural configurations, 30 of them were handled in the framework of this study. The structural optimizations and calculations of vibrational frequencies of baep $\left(\mathrm{C}_{7} \mathrm{H}_{18} \mathrm{~N}_{2} \mathrm{O}_{2}\right)$ were performed using Becke-3Lee-Yang-Parr (B3LYP) density functional methods with $6-311++\mathrm{G}(\mathrm{d}, \mathrm{p})$ basis set. In order to support the reliability of the vibrational assignments, total energy distributions (TED) calculations were done with scaled quantum mechanical (SQM) method. Comparison between the experimental and theoretical results regarding the mean absolute error calculations shows that the results of B3LYP method is able to give satisfactory results for the prediction of vibrational frequencies for the studied molecule.
\end{abstract}

KEY WORDS: 2,2-Bis(aminoethoxy)propane, IR spectra, Raman spectra, Molecular structure, DFT

\section{INTRODUCTION}

Ketal based linkages have recently been investigated for the development of novel acidcleavable polymers those are formulated into the particles to produce potential $\mathrm{pH}$-sensitive drug delivery systems. Besides the stability at physiological $\mathrm{pH} 7.4$, ketal based linages are more sensitive to the acidic environment of tumors and phagosomes than acetal, hyrozone and esters $[1,2]$. Molecules containing primary amines have been paid attention for a wide range of applications such as separation of tungsten from sodium molybdate solution and selective extraction [3].

In order to support and to make the interpretation of vibrational frequencies easier those obtained with infrared and Raman spectroscopic methods, DFT (density functional theory) method is widely used and shows acceptable results for different types of molecules [4-8].

In this study FT-IR and Raman spectroscopic properties, optimized molecular structures of a homobifunctionalized amino ketal, 2,2-bis(aminoethoxy)propane were investigated with experimental and theoretical level. Theoretically obtained vibrational and structural data for the most stable conformer of the title molecule were also compared to the experimentally obtained data and all the findings were also identified and presented in this study.

\section{EXPERIMENTAL}

\section{Materials and methods}

A commercial sample of baep (98\%) was purchased and used without further purification. FTIR spectrum was recorded using Bruker Optics IFS66v/s FTIR spectrometer at a resolution of 2 $\mathrm{cm}^{-1}$. The Raman spectrum was obtained using a Bruker Senterra Dispersive Raman microscope spectrometer with $532 \mathrm{~nm}$ excitation from a $3 \mathrm{~B}$ diode laser having $3 \mathrm{~cm}^{-1}$ resolution in the spectral region of $3700-400 \mathrm{~cm}^{-1}$.

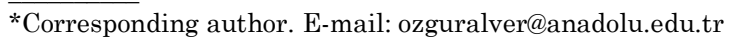


Computational procedure

For the search of stable conformers, many different possible structures were created and 30 of them were examined. During the creation of possible geometric conformers the previously reported studies were taken into account [9-11]. For the search of the stable conformers, 30 forms of baep were first optimized by B3LYP with $6-311 \mathrm{G}++(\mathrm{d}, \mathrm{p})$ basis set in the gas phase. Following the optimization, it was found that some of them $(\mathrm{C} 1, \mathrm{C} 2, \mathrm{C} 4, \mathrm{C} 12, \mathrm{C} 20)$ had negative frequencies so they belonged to transition states and they were no longer considered and some of them were found positive frequencies and henceforth, none of them belonged to a transition state. Among the optimized structures C25 (conformer 25) was found more stable than other conformers. The optimized structures of $\mathrm{C} 25$ and $\mathrm{C} 23$ are given in Figure 1 in which oxygen, nitrogen, carbon and hydrogen atoms were indicated with red, blue, grey and white colors, respectively. Therefore, all the experimental results were compared to C25 conformer. The vibrational wavenumbers of baep were calculated including the same method and the basis set. TED calculations were performed with the scaled quantum mechanical (SQM) program [12, 13]. During the assignments and the matching of the experimental and theoretical vibrational wavenumbers of the title molecule several factors were considered, such as: animation option of the GaussView package program, relative intensities of the vibrational bands and previously reported data in the literature. All the related calculations were conducted with Gaussian 09 program on a personal computer [14].

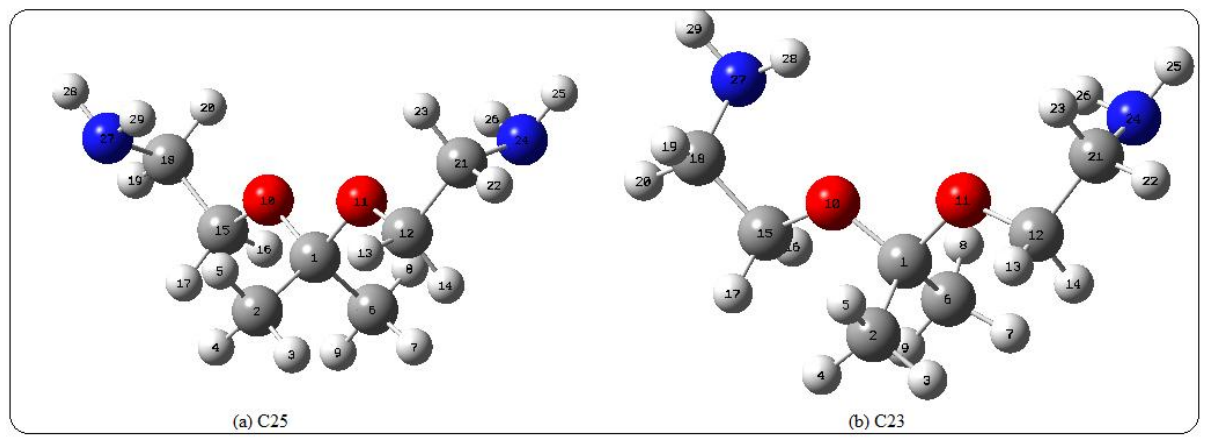

Figure 1. Possible stable conformers of baep optimized with B3LYP/6-311++G(d,p) level of theory.

RESULTS AND DISCUSSION

\section{Geometrical structures}

The lowest energy configuration in the gas phase was found as C25. Furthermore, the optimized energy difference between conformer $\mathrm{C} 25$ and $\mathrm{C} 23$ (Figure 1) is around $0.2 \mathrm{kcal}$, which suggests an abundance of $71 \%$ for $\mathrm{C} 25$ and $29 \%$ for $\mathrm{C} 23$. The rest of the conformers were ignored due to their high optimization energy when compared to C25. Input structures chosen before the optimization and the optimized structures at the end of the calculation using Gaussian program and related level of calculations show that the resultant structure is closely related to how the initial geometry of the molecule was chosen. Indeed some preferred input geometries led to negative or imaginary frequencies at the end of frequency calculations. Several important geometric parameters were mentioned here. For example, for both conformers, N-H and C-O bond lengths were calculated around $1.01 \AA$ and $1.42 \AA$. Dihedral angles of $\mathrm{D}(5 ; 2 ; 1 ; 6)$ and $\mathrm{D}(8 ; 6 ; 1 ; 2)$ for both $\mathrm{C} 25$ and $\mathrm{C} 23$ suggest almost a planar structure with an angle around $177^{\circ}$. 
FT-IR, Raman and DFT studies on the vibrational spectra of 2,2-bis(aminoethoxy)propane 149

The most obvious difference between both conformers is that $\mathrm{NH}_{2}$ groups are on the same side of the plane constructed by $(15 ; 10 ; 1 ; 11$ or $12 ; 11 ; 1 ; 10)$ atoms for $\mathrm{C} 23$ and are on the opposite sides of the mentioned planes for $\mathrm{C} 25$. Some important torsional angles were summarized in Table 1.

Table 1. The magnitude of some important torsional angles of conformer $\mathrm{C} 25$ and $\mathrm{C} 23$.

\begin{tabular}{|l|r|r|}
\hline \multirow{2}{*}{ Torsion angles $\left(^{\circ}\right)$} & \multicolumn{2}{|c|}{ B3LYP/6-311++G(d, $\mathrm{p})$} \\
\cline { 2 - 3 } & 179.6 & $\mathrm{C} 23$ \\
\hline C15-C18-N27-H28 & 61.9 & 60.4 \\
\hline C15-C18-C27-H29 & 175.2 & 179.0 \\
\hline H16-C15-C18-N27 & 64.4 & 55.9 \\
\hline O10-C15-C18-N27 & 170.3 & 64.3 \\
\hline C1-O10-C15-C18 & 52.1 & 179.0 \\
\hline C15-O10-C1-C6 & 73.8 & 51.0 \\
\hline C15-O10-C1-C2 & 168.7 & 74.8 \\
\hline C15-O10-C1-O11 & 168.7 & 167.5 \\
\hline O10-C1-O11-C12 & 170.3 & 166.0 \\
\hline C1-O11-C12-C21 & 64.4 & 169.0 \\
\hline O11-C12-C21-N24 & 176.9 & 64.8 \\
\hline O11-C12-C21-H22 & 179.6 & 176.6 \\
\hline C12-C21-C24-H25 & 61.9 & 179.7 \\
\hline C12-C21-N24-H26 & & 61.8 \\
\hline
\end{tabular}

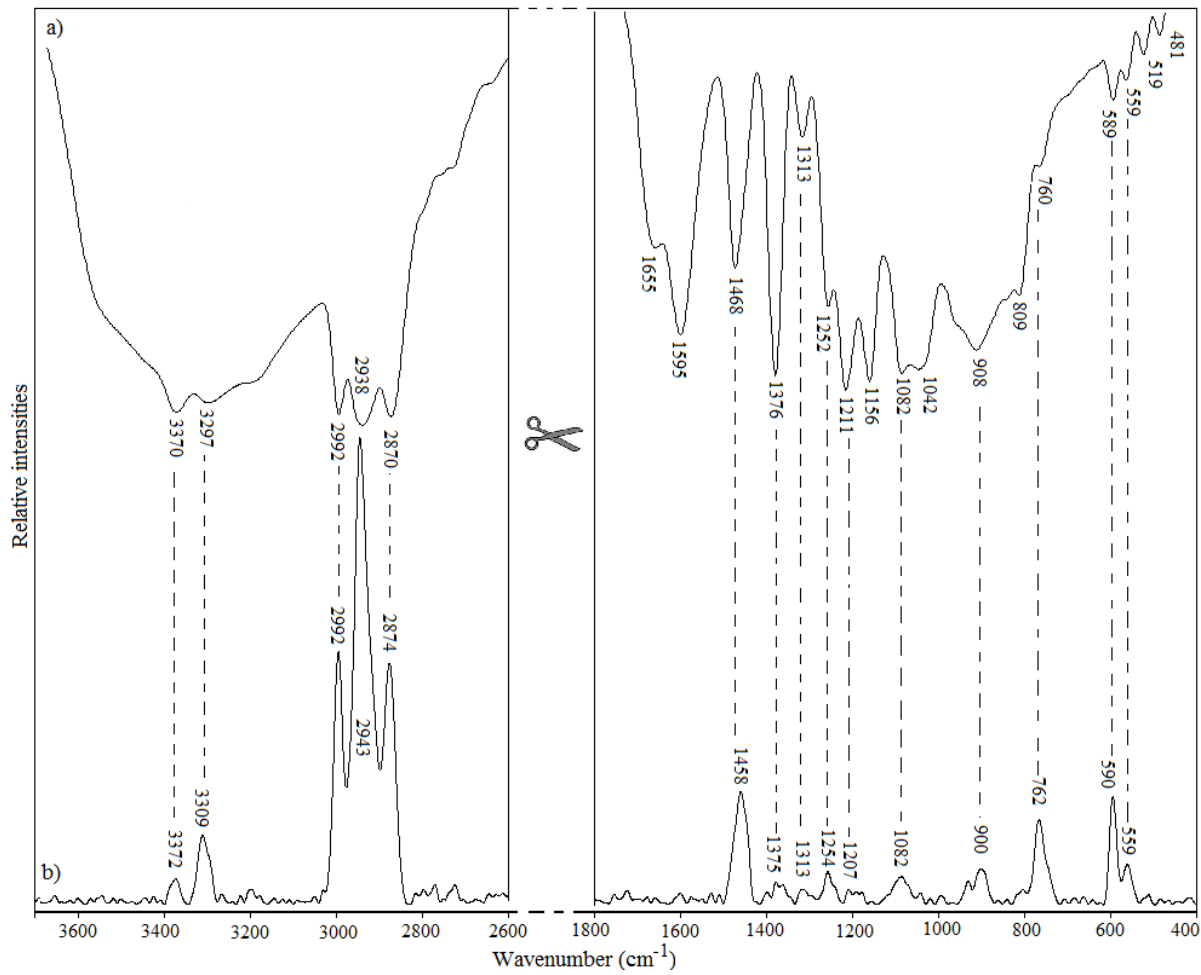

Figure 2. FT-IR (a) and Raman (b) spectra of baep.

Bull. Chem. Soc. Ethiop. 2016, 30(1) 
Vibrational studies of baep

The title molecule baep contains 29 atoms, therefore, it shows 81 normal vibrational modes and it is a member of $C_{1}$ point group with identity (E) symmetry operation. Within the 30 conformers, from $\mathrm{C} 1$ to $\mathrm{C} 30, \mathrm{C} 25$ was found as having the lowest optimization energy showing no negative or imaginary frequencies. As a result, all the experimental results were compared to the theoretical results of $\mathrm{C} 25$ conformer. Theoretical findings for infrared and Raman wavenumbers together with experimental results of the title molecule were shown in Table 2. Experimental (FT-IR and Raman) spectra of baep were presented in Figure 2.

In the high wavenumber region bands appeared at around $3372 \mathrm{~cm}^{-1}(\mathrm{R}), 3370 \mathrm{~cm}^{-1}$ (IR) are the antisymmetric $\mathrm{NH}_{2}$ vibrations while those appeared at $3309 \mathrm{~cm}^{-1}(\mathrm{R})$ and $3297 \mathrm{~cm}^{-1}$ (IR) are due to symmetric $\mathrm{NH}_{2}$ vibrations. The broadened shape of the band at this region could be attributed to the indication of residue of moisture in the sample and intra and intermolecular interactions. The theoretically calculated results for these bands are $3370 \mathrm{~cm}^{-1}$ and $3297 \mathrm{~cm}^{-1}$ and the related TED values are given in Table 2. As seen in Figure 2, antisymmetric $\mathrm{NH}_{2}$ vibration possess higher intensity than symmetric $\mathrm{NH}_{2}$ vibration in IR spectrum and reverse occurs in Raman spectrum. Similar observations were also reported in previous works $[9,15]$. Molecular electronic polarizability of symmetric vibrational form of $\mathrm{NH}_{2}$ changes more when compared to the antisymmetric stretching of $\mathrm{NH}_{2}$. This could explain the differences in band intensities.

Table 2. Comparison of the experimental and calculated vibrational wavenumbers $\left(\mathrm{cm}^{-1}\right)$ of baep in gas phase.

\begin{tabular}{|c|c|c|c|c|c|}
\hline \multirow{2}{*}{$\begin{array}{l}\text { Assignments (C25) } \\
\text { TED }\end{array}$} & \multicolumn{2}{|c|}{ Experimental } & \multicolumn{3}{|c|}{\begin{tabular}{|c|} 
B3LYP/6-311++G(d,p) \\
Gas phase
\end{tabular}} \\
\hline & IR & Raman & $v^{\beta}$ & $\mathrm{I}_{\mathrm{IR}}$ & $\mathrm{I}_{\mathrm{R}}$ \\
\hline$v 27-28(54)+v 27-29(45)$ & 3370 & 3372 & 3370 & 4.85 & 63.85 \\
\hline$v 24-26(53)+v 24-25(44)$ & 3297 & 3309 & 3297 & 2.53 & 122.67 \\
\hline$v 6-8(32)+v 2-5(32)+v 6-7(12)+v 2-4(11)$ & 2992 & 2992 & 2998 & 23.41 & 67.29 \\
\hline$v 2-3(18)+v 6-9(18)+v 2-5(17)+v 6-8(16)+v 2-4(13)$ & 2938 & 2943 & 2926 & 6.79 & 227.57 \\
\hline \multirow[t]{2}{*}{$v 15-16(31)+v 12-13(30)+v 15-17(19)+v 12-14(18)$} & 2870 & 2874 & 2876 & 32.41 & 134.66 \\
\hline & 1655 & - & - & - & - \\
\hline$\delta 28-27-29(27)+\delta 25-24-26(25)+\delta 18-27-29(10)+\delta 21-24-26(9)$ & 1595 & - & 1619 & 63.86 & - \\
\hline$\delta 3-2-5(12)+\delta 4-2-5(12)+\delta 7-6-8(12)+\delta 8-6-9(12)$ & 1468 & 1458 & 1465 & 12.96 & 10.15 \\
\hline$v 15-18(5)+v 12-21(5)$ & 1376 & 1375 & 1372 & 26.05 & 0.26 \\
\hline \multirow{2}{*}{$\delta 15-18-20(10)+\delta 12-21-23(10)+\delta 20-18-27(6)+\delta 24-21-23(6)$} & 1313 & 1313 & 1295 & 6.99 & 0.32 \\
\hline & 1252 & 1254 & - & - & - \\
\hline$\delta 10-15-17(9)+\delta 11-12-14(9)+\delta 20-18-27(5)+\delta 10-15-16(5)$ & 1211 & 1207 & 1217 & 13.43 & 9.01 \\
\hline$v 11-12(7)+v 10-15(7)+\delta 12-21-22(6)+\delta 15-18-19(6)$ & 1156 & - & 1162 & 4.65 & 0.91 \\
\hline$v 15-18(14)+v 12-21(14)+v 21-24(12)+v 18-27(12)$ & 1082 & 1082 & 1082 & 34.68 & 1.15 \\
\hline$v 18-27(18)+v 21-24(17)$ & 1042 & - & 1041 & 8.85 & - \\
\hline$v 1-10(18)+v 1-11(18)$ & 908 & 900 & 897 & 61.93 & 0.16 \\
\hline$\delta 21-24-26(9)+\delta 18-27-29(9)+\delta 21-24-25(6)+\tau 19-18-27-29(6)$ & 809 & - & 803 & 38.50 & 2.76 \\
\hline$v 1-10(10)+v 1-11(10)+v 10-15(7)+v 11-12(7)$ & 760 & 762 & 772 & 34.02 & 5.94 \\
\hline \multirow[t]{3}{*}{$\delta 1-11-12(13)+\delta 1-10-15(13)+\delta 10-15-18(5)+\delta 11-12-21(5)$} & 589 & 590 & 590 & 8.86 & 1.20 \\
\hline & 559 & 559 & - & - & - \\
\hline & 519 & - & - & - & - \\
\hline$\delta 6-1-10(7)+\delta 2-1-11(7)+v 1-2(7)+v 1-6(7)$ & 481 & - & 484 & 5.25 & 0.37 \\
\hline
\end{tabular}

IR: Infrared; $v^{\beta}$ : Wavenumbers scaled with SQM methodology; $\mathrm{I}_{\mathrm{R}}$ : Infrared intensities $(\mathrm{km} / \mathrm{mol})$; $\mathrm{I}_{\mathrm{R}}$ : Raman activities $\left(\AA^{4} / \mathrm{amu}\right)$.

$\mathrm{CH}$ stretching vibrations experimentally/theoretically appeared at $2992 \mathrm{~cm}^{-1}$ (IR, R)/2998

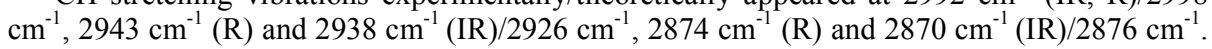


Related TED values can be seen in Table 2 for all vibrations. While $\mathrm{NH}_{2}$ bending vibrations or more precisely scissoring vibrations of baep seem Raman inactive or its intensity is too low to describe it meaningfully (Figure 2), its IR band appears at $1595 \mathrm{~cm}^{-1}$ as a strong band which is theoretically calculated as $1619 \mathrm{~cm}^{-1}$. The band appeared at $1468 \mathrm{~cm}^{-1}$ (IR) and $1458 \mathrm{~cm}^{-1}$ (R) are due to stretching modes of $\mathrm{CH}_{3}$. This band is theoretically predicted as $1465 \mathrm{~cm}^{-1}$. The band at $1313 \mathrm{~cm}^{-1}$ (IR, R) which is theoretically calculated as $1295 \mathrm{~cm}^{-1}$ is due to CC stretching vibrations (Table 2). Measurements made under $1313 \mathrm{~cm}^{-1}$ have revealed mixed type of vibrations as can be seen in Table 2 .

\section{CONCLUSIONS}

Experimental and theoretical vibrational IR and Raman spectra and structural properties of baep were analyzed with $B 3 L Y P / 6-31++G(d, p)$ level of theory. In brief, following results can be summed up: (i) B3LYP/6-31++G(d,p) level of theory came up with acceptable results in the calculation of vibrational frequencies for the title molecule following the application of SQM method. (ii) Among the examined conformers, C25 conformer was found having the lowest optimized energy in the gasphase. (iii) It was seen that the optimized output structure with Gaussian program strongly depends on the input configuration of the investigated molecule. Therefore, it is important to identify a various range of possible structures before optimization procedure. Observation of no negative frequencies does not always mean that the obtained structure has the lowest optimization energy.

\section{REFERENCES}

1. Khaja, S.D.; Lee, S.; Murthy, N. Biomacromolecules, 2007, 8, 1391.

2. Lee, S.; Yang, S.C.; Heffernan, M.J.; Taylor, W.R.; Murthy, N. Bioconjugate Chem. 2007, 18,4 .

3. Ning, P.; Cao, H.; Zang, Y. Sep. Purif. Technol. 2009, 70, 27.

4. Alver, Ö.;Parlak, C.; Şenyel, M. Bull. Chem. Soc. Ethiop. 2009, 23, 85.

5. Karabacak, M.; Sinha, L.; Prasad, O.; Asiri, A.M.; Çınar, M. Spectrochim. Acta A 2013, 115, 753.

6. Alver, Ö.; Parlak, C. Vib. Spectrosc. 2010, 54, 1.

7. Becke, A.D. J. Chem. Phys. 1993, 98, 5648.

8. Alver, Ö.; Parlak, C.; Şenyel M. J. Mol. Struct. 2009, 923, 120.

9. Alver, Ö.; Parlak, C. J. Theor. Comput. Chem. 2010, 9, 667.

10. Durig, J.R.; Beshir, W.B.; Godbey, S.E.; Hizer, T.J. J. Raman Spectrosc. 1989, 20, 311.

11. Stidham, H.D.; Durig, J.R. Spectrochim. Acta A 1986, 42, 105.

12. Rauhut, G.; Pulay, P. J. Phys. Chem. 1995, 99, 3093.

13. Baker, J.; Jarzecki, A.A.; Pulay, P.J. Phys. Chem. A 1998, 102, 1412.

14. Frisch, M.J.; Trucks, G.W.; Schlegel, H.B.; Scuseria, G.E.; Robb, M.A.; Cheeseman, J.R.; Scalmani, G.; Barone, V.; Mennucci, B.; Petersson, G.A.; Nakatsuji, H.; Caricato, M.; Li, X.; Hratchian, H.P.; Izmaylov, A.F.; Bloino, J.; Zheng, G.; Sonnenberg, J.L.; Hada, M.; Ehara, M.; Toyota, K.; Fukuda, R.; Hasegawa, J.; Ishida, M.; Nakajima, T.; Honda, Y.; Kitao, O.; Nakai, H.; Vreven, T.; Montgomery Jr., J.A.; Peralta, J.E.; Ogliaro, F.; Bearpark, M.; Heyd, J.J.; Brothers, E.; Kudin, K.N.; Staroverov, V.N.; Kobayashi, R.; Normand, J.; Raghavachari, K.; Rendell, A.; Burant, J.C.; Iyengar, S.S.; Tomasi, J.; Cossi, M.; Rega, N.; Millam, J.M.; Klene, M.; Knox, J.E.; Cross, J.B.; Bakken, V.; Adamo, C.; Jaramillo, J.; Gomperts, R.; Stratmann, R.E.; Yazyev, O.; Austin, A.J.; Cammi, R.; Pomelli, C.; Ochterski, J.W.; Martin, R.L.; Morokuma, K.; Zakrzewski, V.G.; Voth, G.A.;Salvador, P.; Dannenberg, J.J.; Dapprich, S.; Daniels, A.D.; Farkas, O.; Foresman, J.B.; Ortiz, J.V.; Cioslowski, J.; Fox, D.J.; Gaussian 09, Revision A.1, Gaussian Inc.: Wallingford, CT; 2009.

15. Alver, Ö.; Parlak, C.; Şenyel, M. J. Mol. Struct. 2009, 923, 120. 